\title{
Teaching High School Students Applied Logical Reasoning
}

\author{
Dan Bouhnik and Yahel Giat \\ Jerusalem College of Technology, Jerusalem, Israel
}

bouhnik@jct.ac.il; yahel@jct.ac.il

\section{Executive Summary}

The rapid changes in information technology in recent years have rendered current high school curricula unable to cope with student needs. In consequence, students do not possess the proper skills required in today's information era. Specifically, many students lack the skills to search efficiently for information. Moreover, even when abundant information is available to them, students are unable to critically read, analyze, and evaluate it.

To address these problems we developed a high school course designed to provide students with applied logical tools. The course was developed for two different student groups: social sciencesoriented students and exact sciences-oriented students. It is composed of several parts whose contents depend on the students' orientation. This course is part of a broader program whose purpose is a comprehensive study and understanding of logical and concept-based systems.

The course was taught to three high school student groups with different academic orientation and age. Two of the groups majored in social sciences and the third group majored in exact sciences. Of the two social sciences groups, one was composed of senior students and the second of junior students. To assess the effectiveness of the course, we gave each group an exam testing their critical reasoning skills. This exam was administered in the first week of the course. The groups were given a similar exam at the end of the course. In addition, after the completion of the course the students were asked to fill in a questionnaire about the course and its effect on them.

The purpose of the pre-course and post-course exams was to examine the objective change in the assessment of students' skills. The purpose of the questionnaire was to test overall satisfaction and the students' subjective assessment of the change in their skill. The results of this initial examination were very encouraging. We found a significant improvement in the students' critical reading skills. In addition, students felt they had better analytical and critical skills. They reported a change in their reading behavior with most students reporting a more critical and logical approach and a better ability to understand underlying assumptions and separate opinion from fact.

We believe this paper makes three important contributions. First, the course we describe is novel in adapting university level courses in applied logic for high school students. Secondly, it is

Material published as part of this journal, either on-line or in print, is copyrighted by the publisher of the Journal of Information Technology Education. Permission to make digital or paper copy of part or all of these works for personal or classroom use is granted without fee provided that the copies are not made or distributed for profit or commercial advantage AND that copies 1) bear this notice in full and 2) give the full citation on the first page. It is permissible to abstract these works so long as credit is given. To copy in all other cases or to republish or to post on a server or to redistribute to lists requires specific permission and payment of a fee. Contact Editor@JITE.org to request redistribution permission. modular enough to allow exact sciences-oriented students to combine critical reading with computer and mathematical topics. Thirdly, we report our experience of teaching this course in the high school level and find that this course improved skills essential to the students and that students responded positively to it. 
Keywords: Reasoning, Applied Logic, Critical Thinking, Computation, Information Technology, Education

\section{Introduction}

"For we let our young men and women go out unarmed in a day when armor was never so necessary. By teaching them all to read, we have left them at the mercy of the printed word. By the invention of the film and the radio, we have made certain that no aversion to reading shall secure them from the incessant battery of words, words, words. They do not know what the words mean; they do not know how to ward them off or blunt their edge or fling them back; they are a prey to words in their emotions instead of being the masters of them in their intellects..." Dorothy Sayers, "The Lost Tools of Learning", speech at Oxford, 1947.

Dorothy Sayers' lamentation is as relevant as ever. As we go deeper and deeper into the "Information Revolution" our students face an ever increasing variety of channels of information. Due to their unrestricted nature, however, these sources of information are more often than not conflicting, partial, biased, and distorting (Stanford Persuasive Technology Lab, 2004). Thus, instead of utilizing this abundant information to produce better informed students, we often find that students are unable to distinguish true from false, separate fact from fiction, identify the underlying motives, and reach sound and reasoned opinions (Lighthall \& Haycock, 1997; Rothenberg, 1997). In order to cope with today's multiplicity of information sources and promote development of learned and informed students, instruction in critical reading and logical reasoning is of paramount importance (Fitzgerald, 2005).

In the present work we describe a high school course designed to provide students with applied logical tools. Currently, high school students are not typically offered instruction in logical reasoning, and must instead wait to gain these tools in college. (In this paper we use the term 'college' as it is used in the USA, namely, to describe tertiary education). In our opinion, high school constitutes an appropriate age-range and educational context in which to teach logical skills; delaying such instruction until college simply prolongs - if not perpetuates - the aforementioned problems. The content of the course in question takes into account student age and, accordingly, should place strong emphasis on practice and application alongside theory. In addition, we take into account two primary academic orientations, differentiating between social sciences and exact sciences. In light of this distinction, the course was designed to include several chapters whose contents depend on academic orientation.

More broadly, this course was part of a two-year program of a comprehensive study and understanding of logical and concept based systems. The logic program covered different topics in modern logic and its application. These topics were divided into the following modules: logical reasoning and deductions, Boolean algebra and digital systems, inductions, paradoxes, and computation. The course that we describe in this paper was the first year course of the program. It fully covered the first module (logical reasoning and deductions) and most of the second module (Boolean algebra). In addition, it served as an introduction to the other modules of the program. Throughout the course we focused on motivating the students to understand the importance of acquiring applied logical skills.

\section{Literature Review}

This paper is directly related to two fields of research: education of applied logic and information technology. 
Modern logic has emerged in the twentieth century (see Gabbay \& Woods, 2004, for a historical review). It was the theoretical force that drove Turing's (1936) seminal work that laid the foundation for computing science. Our course includes theoretical computing issues such as the Theorem of Incompleteness, The Halting Problem, and NP Problems (Boolos \& Jeffrey, 1974; Lewis \& Papadimitriou, 1981).

Modern logic is also applied in the field of critical thinking, and its importance is manifested in the existence of numerous critical reading textbooks and other printed sources (e.g. Brookfield, 1987; Browne, 2001; Browne \& Keeley, 2006; Kahane \& Cavender, 2006; Paul, 1990; Ruggiero, 1991). Kahane (1980) claims that cogent reasoning must meet three criteria: believable premises, the search and inclusion of all relevant information, and valid arguments. Kahane (1989) claims that many critical thinking courses overemphasize the third criterion, and as a result, students do not study critical reasoning, but instead simply receive formal logic training. Paul (1982) argues that when teachers emphasize the third criterion over the first two criteria, students lack important critical reasoning skills such as refraining from prejudice. Consequently, students do not improve their ability to deal effectively with life's everyday problems. Kahane (1989) therefore argues that engaging students with real-life problems is an effective vehicle to shift back the emphasis of critical thinking courses to all three criteria.

Kahane's arguments are even more significant when teaching high school students (rather than college students) who are still learning how to confront real-life problems. While Kahane views critical thinking as its own topic of study, other researchers emphasize the need to infuse critical thinking into every aspect of students' learning. Swartz, Fischer, and Parks (1998), for example, claim that infusing critical and creative thinking into the high-school classroom improves student learning by eliminating hastiness, narrow-mindedness, obscurity, and lack of focus. Pascarella and Terenzini (1991) provide another argument for teaching students critical thinking before they go to college. They report that while the effects of learning critical thinking on college freshmen are profound, such effects quickly depreciate over time. Studying critical thinking in high school allows students to incorporate these skills into their learning process at an earlier age, thereby providing continuity and a strong foundation from which to expand during college level instruction, ultimately resulting in greater skill retention. This approach can be coupled with the scaffolding approach of Thomas, Davis, and Kazlauskas (2007), which is implemented in a variety of college courses.

Our course is also closely related to the field of the education of information technology. The American Library Association (1998) states, "To be information literate, a person must be able to recognize when information is needed and have the ability to locate, evaluate, and use effectively the needed information." Shapiro \& Hughes (1996) find that computer literacy is the central skill for improving information literacy. In spite of the growing importance of computer literacy, it is not so obvious that students are sufficiently computer literate. In a recent article, Andriole (2006) describes how educators respond to the recent, dramatic changes in the field of information technology with a new computer science curriculum. Andriole claims that the new curriculum does not improve student ability to adapt to the new business environment and, therefore, suggests a curriculum that emphasizes practice over theory. A similar problem is described by Johnson, Bartholomew and Miller (2006) and Bartholomew (2003) who describe how college students' computer literacy is decreasing over time. They, too, find that MBA students' computer literacy does not meet prospective employers' expectations and needs. The term computer literacy is frequently interchanged with the term digital literacy. A recent attempt to define digital literacy broadly is made by Eshet-Alkalai (2004) who views information literacy as a component of digital literacy. Whether one takes the Shapiro \& Hughes (1996) approach or the Eshet-Alkalai (2004) approach to the relationship between information literacy, computer literacy, and digital literacy, it is clear 
that they are highly connected and progress in either literacy inevitably leads to progress in the other forms of literacy.

Eshet-Alkalai and Geri (2007) find that students, particularly of a younger age, have insufficient critical thinking and propose to infuse student classes with digital literacy skills. Digital literacy is required from students as a direct result of the digital environment in which they are growing (see Eshet, 2002). Critical thinking allows students to assess information by sorting out subjective, biased, or even false information and has become a key factor in transforming students into efficient information consumers (Kerka, 1999; Salomon, 2000). Resnick (2002) explains that this digital literacy era must be navigated cautiously because teachers tend to focus on digital tools, such as computers, only as sources of knowledge. Instead, Resnick claims, teachers should instruct students how to use these tools for the creation and expansion of students' ability to acquire knowledge. We, therefore, designed the curriculum of our program to achieve this goal by creating a strong theoretical foundation that is reinforced with practical tools. These tools follow Andriole's (2006) and Kahane's (1989) call for stressing application to ensure that students' learning is relevant in the ever-changing digital environment.

The critical thinking elements of our course are similar to the high school course reported by Eshet-Alkalai and Geri (2007). Other examples of such courses can be found in various physical and virtual locations, notably The Center for Critical Thinking located in Sonoma State University (Rohnert Park, California) and the Critical Thinking Community website. The main difference between our course and these courses is that we provide a broader skill set of applied and theoretical logical tools. We believe, as in Eshet-Alkalai (2004), that critical thinking is but one, albeit important, facet of digital literacy.

\section{Course Curriculum and Goals}

The central goal of the course describe herein was to improve student knowledge of different applied logic fields. This goal may be divided into the following sub-goals:

a) Improve critical reasoning skills.

b) Improve ability to apply logical reasoning in speech and writing.

c) Improve ability to search, retrieve, analyze, and evaluate information.

d) Improve ability in other applied logic fields, such as computation and digital systems.

The course is the first year course of a two-year program of modern theoretical and applied logic studies. This program is divided into six modules.

1. Reasoning and logical deductions: Classifying, interpreting, and assessing arguments, rhetorical arguments, and fallacies (Copi, 1979; Copi \& Cohen, 2004 and Epstein, 2001a, 2002).

2. Boolean algebra: Covering topics from basic logical operations through the construction of logical electronic units (Katz \& Borriello, 2004; Markovitz, 2005; Roth, 2004).

3. Inductions: Probability theory, making the distinction between inductions and deductions (Copi \& Cohen, 2004; Hacking, 2001).

4. Paradoxes: Fallacious paradoxes, set-theoretical paradoxes (Russel's Paradox) (Rescher, 2001; Sainsbury, 1995).

5. Computation: Godel's theorem (Godel, 1962), Turing machine, the Halting problem, and reductions (Boolos \& Jeffrey, 1974; Lewis \& Papadimitriou, 1981). 
6. Special topics: The topics chosen for this part of the program expand the students' knowledge of the other parts of the program. These topics include: Synchronous and asynchronous digital design (Mano, 2001; Wakerly, 2005) and axiom systems for natural deductions.

The course fully covered the Reasoning and logical deductions module and most of the Boolean algebra module. In addition, it served as an introduction to the other modules of the program. These modules are taught in the second year of this program. It was taught throughout a full school year, 3 hours weekly (approximately 90 class hours).

The content of the course is divided into the following chapters:

1. Principals of reasoning (30 hours): Reasoning was at the core of the course and was allotted a considerable portion of the course's duration. This chapter introduced the students to the concepts and terms of logical reasoning. The students learned about statements, arguments, conclusions, interpretation, and distinguishing between fact and interpretation. The students learned how to present arguments via propositional calculus.

2. Logical-algebraic tools (20 hours): Students were introduced to logical variables; operators, and functions. They learned table representation and minimization of logical functions and how to employ algebraic tools such as Karnaugh Maps and the QuineMccluskey Method. When teaching this chapter to the exact sciences-oriented students we emphasized the logical algebraic tools and their application in computer science and digital systems. When teaching the social sciences-oriented students this course, we focused on the application of these algebraic tools in data mining, internet searches, high level coding, and database querying.

3. Assessments, deductions and inductions (20 hours): The issues covered in this chapter included the ability to assess the validity of an argument; positive and negative deductions; rules of inference, and inductive arguments. The emphasis in the chapter for the exact sciences-oriented students was on probability theory involving inductive arguments, and for the social sciences-oriented students was on the validity of logical deductions (Copi, 1979 and Copi \& Cohen, 2004).

4. Special topics (10 hours): The topics covered in this chapter were diverse and intended to introduce the students to deeper issues in the study of logic and the rest of the logic program. The exact sciences-oriented students were taught completeness of logical systems. The social sciences students were introduced to paradoxes. Both groups were introduced to predicate symbols (Epstein, 2001b).

5. Debates (10 hours): This chapter was interwoven with other chapters of the course. In the early stages of the course the debates were directed by the teachers, and the reasoning tools learnt in the first chapter were stressed. In later stages of the course, the students practiced mini-debates and analyzed their peers' debates and arguments. In addition, students wrote papers about different topics where they applied the theory learnt throughout the course. The course's final requirement was an essay or a debate testing the students' skills in applying the theory.

The chapters of the course may be taught in different levels of depth, depending on the audience.

The course bibliography includes: Berg, 1998; Copi, 1979; Copi and Cohen, 2004; Epstein, 2001a, 2001b, and 2002; Rescher, 2001; Sainsbury, 1995; Kahane \& Cavender, 2006; Browne \& Keeley, 2006; Lewis \& Papadimitriou, 1981 and Boolos \& Jeffrey, 1974. 


\section{Research Questions}

We examined whether the course we designed achieved its first sub-goal. We focused on this subgoal because we considered it to be the most important sub-goal of the course. Our research is driven by two central questions:

1. What is the course's objective assessment of improvement (OAI) in student skills? This question investigates whether an objective examiner will find that the students' skills, as specified in the course's goals, have improved.

2. What is the course's subjective assessment of improvement (SAI) in student skills? We examined whether the students felt that their skills have improved. In addition, we examined whether students felt this course is important and whether they applied skills acquired during the course.

In addition to these questions, we examined a third question, secondary to the first two:

3. What are the differences, if any, between the social and exact sciences groups? We stressed inductive arguments (probability) and digital systems to the exact sciences students whereas we emphasized deductive arguments, information technology, and evaluation to social science students. We investigated whether the two emphases resulted in different effects on objective and subjective assessments of improvement in students' critical reasoning skills.

Eshet-Alkalai and Geri (2007) claim that students' critical thinking skills increase with age. Accordingly, we hypothesized that the younger students will have lower skills prior to the course and will therefore benefit from the course more than the older groups. Formally:

H1: Younger students will have lower critical thinking skills prior to the course than older students.

H2: Younger students will have a higher OAI than older students.

Since the course stresses application over theory and reinforces the theoretical material with students' day to day life experiences we hypothesized that the SAI will be correlated with the OAI. Thus:

H3: Younger students will have a higher SAI than older students.

H4: There will be a positive relationship between the subjective and objective assessments of improvement.

Finally, we tested whether academic orientation affected the OAI and SAI:

H5: Academic orientation will affect the OAI.

H6: Academic orientation will affect the SAI.

\section{Methodology}

\section{Participants}

We taught this course to three student groups, which we labeled G-12S, G-12E, and G-11S. Groups G-12S and G-12E were twelfth-grade students. Group G-12S comprised 26 students who majored in social sciences, and G-12E comprised twenty-one students who majored in exact sciences. Group G-11S comprised twenty-eight eleventh-grade students who majored in social sciences. A summary of the characteristics of these groups is presented in Table 1 . The school is a private Jewish high school (grades 9-12, ages 15-18) located in a major city in central Israel. This 
school is representative of other high schools in Israel, as private high schools are publicly funded and must meet, by law, the same core learning requirements as public high schools. The learning fields in this school are similar to other high schools in Israel and all students must take the national matriculation exams in Math; Hebrew; English, and various social sciences subjects. In addition, as with any high school in Israel, the students must take at least one advanced class in Exact Sciences (such as Physics; Chemistry, and Computer Sciences) or Social Sciences (such as History, Geography, and Communications). This school may be also representative for high schools in different countries as many subjects that are learnt in this school are also learnt in many high schools throughout the world.

Table 1: Groups Characteristics

\begin{tabular}{|c|c|c|c|}
\hline Group Label & Sample Size & Grade (Age) & Orientation \\
\hline G-12S & 26 & Grade 12(17-18) & Social Sciences \\
\hline G-12E & 21 & Grade 12 (17-18) & Exact Sciences \\
\hline G-11S & 28 & Grade 11 (16-17) & Social Sciences \\
\hline
\end{tabular}

Since the course was part of a two-year program, only group G-11S, which was in the eleventhgrade, was scheduled to take the rest of the program in the following year (their twelfth-grade year). We decided that this course should be taken regardless of whether one takes the rest of the applied logic program or not. Accordingly, we decided that groups G-12E and G-12S, who were in their last school year, should nevertheless be given this course. Groups G-12E and G-12S allowed us to compare social sciences students and exact sciences students and to further adapt the curriculum to these distinct groups in future years. We examined whether the first sub-goal was achieved, namely, whether the students have improved their critical reasoning skills. As the critical reasoning component of the course syllabus is almost identical for the social and exact sciences students, we claim that any differences that we may find should be attributed to the two student populations - social and exact science students - and not to the different course emphases.

\section{Instruments}

To answer the first research question, the students were administered an exam at the outset of the course that tested simple critical reasoning skills. A similar exam was given to the students towards the end of the course. Each exam comprised fifteen questions grouped into three sets of five questions each. Each question began with a sentence or a short paragraph. In the first group of questions the students were required to identify the premises and the conclusions in the paragraph and how they relate to each other (i.e. which premises lead to which conclusions). The next group of questions required students to identify correct and erroneous logical deductions. The final group of questions required the students to identify hidden premises. The questions were edited quotes from contemporary news; political statements; judiciary rulings, or day-to-day life situations. In the Appendix we have provided an example question for each group. Students were given 60 minutes to complete the exam.

In addition to these pre-course and post-course exams the students were assessed during the course through a number of methods, including written and oral exams, papers, and debates. However, for the purpose of examining the OAI in students' skills we used only the pre-course and the post-course exams.

The SAI focused only on the improvement in critical thinking skills. During the course and following the course we engaged students in many discussions about their attitudes towards the course and its effect on their critical reading. To examine the SAI quantitatively, we asked the 
students to fill out an anonymous questionnaire one week after the course was completed and before receiving their final grade. The questionnaire was administered to the students by their home-room teachers and was manually completed by the students. The home-room teachers handed us the questionnaires results in Excel format. The questionnaire consisted of three questions measuring how the students subjectively assess the course's effect. The first two questions measure the SAI and the third questions measures the importance of the course as viewed by the students.

1. Q1: Improvement: To what extent did the course improve your critical reasoning?

2. Q2. Increased Usage: To what extent do you employ the techniques studied in this course in your daily life more than you have before taking the course?

3. Q3. Importance: Do you believe this course is important?

The students were asked to answer each question with a number between zero and four with a low value indicating "no change / low" and a high value indicating "significant change / high".

In addition to these three questions, we examined the differences, if any, between the social sciences group and the exact sciences groups.

\section{Limitations}

This course was developed by us and therefore one possible bias is our hope for its success. To mitigate this bias we had separate roles in this course. The course was taught by the first author whereas the second author administered the pre-course and post-course exams as well as the questionnaire.

Another possible bias is the fact that the pre-course exam and the post-course exam were similar exams, which inevitably leads to a positive OAI.

The SAI may be biased due to students' fear of reprisal or the students' desire to please their teachers. To mitigate this bias the questionnaire was anonymous and was given to the students only when they knew that the course's final grade was already determined. Moreover, the questionnaire was completed by the students before they received their final grade so that their grade would not influence their response. In addition, the students feel comfortable with questionnaires as they provide anonymous feedback twice a year on each class they take. Another limitation is that the questionnaire measuring the SAI comprised of only three questions following school policy on the matter. This policy was set in agreement with students to ensure their full participation in these feedback questionnaires. To mitigate this limitation we complemented our measurement of the SAI with informal interviews and discussions.

\section{Results}

\section{OAI}

The results suggest that the students significantly improved their critical reasoning. Table 2 summarizes the OAI in the students' basic critical reasoning skills. The Pre-course Grade and the Post-Course Grade columns describe the average (M) and standard deviation (SD) of the precourse exam and post-course exam grades, respectively. The OAI is the difference between the post-course exam grade and the pre-course exam grade. The improvement rate is the percent of students that have improved their score from the pre-course exam to the post-course exam. 
Table 2: OAI in critical reasoning skills

\begin{tabular}{|c|c|c|c|c|c|c|c|c|}
\hline \multirow{2}{*}{ Group } & \multirow{2}{*}{$\begin{array}{c}\text { Sample } \\
\text { Size }\end{array}$} & \multicolumn{2}{|c|}{$\begin{array}{c}\text { Pre-Course } \\
\text { Grade }\end{array}$} & \multicolumn{2}{|c|}{$\begin{array}{c}\text { Post-Course } \\
\text { Grade }\end{array}$} & \multicolumn{2}{|c|}{ OAI } & \multirow{2}{*}{$\begin{array}{c}\text { Improvement } \\
\text { Rate }\end{array}$} \\
\cline { 3 - 7 } & & M & SD & M & SD & M & SD & \\
\hline G-12S & 26 & 31 & 38 & 85 & 17 & 54 & 33 & $85 \%$ \\
\hline G-12E & 21 & 38 & 35 & 83 & 17 & 45 & 30 & $86 \%$ \\
\hline G-11S & 28 & 14 & 30 & 82 & 19 & 67 & 31 & $93 \%$ \\
\hline All & 75 & 27 & 35 & 83 & 17 & 57 & 32 & $88 \%$ \\
\hline
\end{tabular}

An independent samples heteroscedastic $t$ test was performed comparing the mean pre-course grades and OAI of the eleventh grade students (G-11S) and the twelfth-grade students (the combined group of G-12S and G-12E). The mean pre-course exam of the younger group was significantly lower than the older group $(\mathrm{t}(27)=2.65, \mathrm{p}<0.02)$, supporting the hypothesis $\mathrm{H} 1$. The mean OAI of G-11S was found significantly lower than the twelfth-grade students $(\mathrm{t}(27)=2.34$, $\mathrm{p}<0.05$ ), supporting the hypothesis $\mathrm{H} 2$.

An independent samples heteroscedastic $t$ test comparing the mean OAI of the exact sciences group (G-12E) and the social sciences students (the combined group of G-12S and G-11S) did not support the hypothesis H5.

\section{SAl and the Course's Importance}

The students reacted very positively to the course. Our impression from the course is that they were very engaged with the material throughout the course and invested a considerable amount of time preparing their debates and papers. Anecdotal evidence gathered from other teachers indicated that students' enthusiasm was felt in other courses they took, such as history, religion, and computer sciences. To measure quantitatively the students' subjective assessment of the course's effect, we asked them to complete a questionnaire. The students' answers to the questionnaire and the SAI are displayed in Table 3. The SAI is the average score of the scores for the first two questions (the improvement and the increased usage questions).

Table 3: Subjective assessment of critical reasoning skills (response to questionnaire)

\begin{tabular}{|c|c|c|c|c|c|c|c|c|c|}
\hline Group & $\begin{array}{c}\text { Sample } \\
\text { Size }\end{array}$ & \multicolumn{2}{|c|}{$\begin{array}{c}\text { Q1: } \\
\text { Improvement }\end{array}$} & \multicolumn{2}{c|}{$\begin{array}{c}\text { Q2: Increased } \\
\text { Usage }\end{array}$} & \multicolumn{2}{c|}{ SAI } & \multicolumn{2}{c|}{$\begin{array}{c}\text { Q3: } \\
\text { Importance }\end{array}$} \\
\cline { 3 - 9 } & & M & SD & M & SD & M & SD & M & SD \\
\hline G-12S & 26 & 2.69 & 0.79 & 2.81 & 0.63 & 2.75 & 0.64 & 3.15 & 0.92 \\
\hline G-12E & 21 & 3.29 & 0.72 & 3.67 & 0.48 & 3.48 & 0.51 & 3.57 & 0.68 \\
\hline G-11S & 28 & 3.18 & 0.86 & 3.29 & 0.9 & 3.23 & 0.78 & 3.61 & 0.83 \\
\hline All & 75 & 3.04 & 0.83 & 3.23 & 0.78 & 3.13 & 0.72 & 3.44 & 0.84 \\
\hline
\end{tabular}

All student groups found this course important. In addition, students generally reported a high SAI. We found that the younger students (G-11S) had a higher mean SAI than G-12S but lower than G-12E. Thus, the hypothesis H3 was not supported. An independent samples heteroscedastic $t$ test comparing the mean SAI of the exact sciences group (G-12E) and the social sciences stu- 
dents (the combined group of G-12S and G-11S) revealed that the exact sciences students were significantly higher $(\mathrm{t}(20)=3.43, \mathrm{p}<0.005)$, in support of the hypothesis H6.

A Pearson correlation addressed the relationship between the OAI and SAI for each group and the entire sample. Results are reported in Table 4.

Table 4: The correlation between the OAI and SAI for the different groups

\begin{tabular}{|c|l|}
\hline Group & Correlation \\
\hline G-12S & $\mathrm{r}(24)=0.24$ \\
\hline G-12E & $\mathrm{r}(19)=0.24$ \\
\hline G-11S & $\mathrm{r}(26)=0.47^{*}$ \\
\hline All & $\mathrm{r}(73)=0.36^{*}$ \\
\hline
\end{tabular}

Note: $* \mathrm{p}<0.01$

All groups had a weak positive relationship between the subjective and objective assessments of improvement scores. Specifically, for the entire sample this relationship was significant and thus the hypothesis H4 was supported.

\section{Discussion}

Our course was given to three groups totaling 75 students in one school during the same year. Due to the small sample size and the small number of groups we must approach the results of this research with the appropriate caution.

The research objective was to examine whether the course had affected the objective and subjective assessment of the students' critical thinking. We found that this course has improved both assessments. We found that the younger group scored lower in the pre-course exam and had a higher OAI than the older groups. The prior difference may be explained by differences in intellectual maturity between age levels. Nevertheless, despite differences in pre-course test scores, the younger group's final scores were comparable to the older groups. It is important to note, however, that the age differences between the groups are relatively small (only one year on average). We were unable to demonstrate that academic orientation affected the OAI. The students reported high SAI, with the exact sciences students reporting the highest assessment of improvement. A possible explanation of why the exact sciences students reported a higher SAI is that our applied logical reasoning course was related to other courses that this group was taking (such as digital systems and computation). Therefore, they may have found this course supplementing their understanding of other material as well as the subject matter of our course. In contrast, the social sciences students felt this course was academically "isolated" and did not fully appreciate the contribution of the course to their critical thinking. Indeed, students' anecdotal comments supported such an explanation. All student groups considered the course as important with nonsignificant changes between the groups. The correlation between the subjective and objective assessments of improvement was positive but not very high (see Table 4). This indicated that students are only somewhat accurate in assessing their own improvement.

Anecdotal discussions with the exact sciences students suggested that they felt more strongly than the social studies students about the different applications of the course, especially the Boolean algebra theory and the digital systems design. The social science students, on the other hand, reported to us that they use these tools to critique and evaluate information and to search for information on the internet more efficiently. While these students felt that the course considerably in- 
creased their skills, they believe that they possessed those skills even before taking the course and therefore their reported SAI is not as high as their counterparts in exact sciences.

The course that we developed addresses the issues raised by researchers with respect to critical thinking. In particular we followed Kahane's (1980) guidelines and designed the course to provide students with applicable tools for critical reasoning. Every theoretical topic is demonstrated with practical real-life examples and students are required to demonstrate their ability to apply the material in debates, essays, speeches, and the evaluation of internet resources (see, for example, Fitzgerald, 2005). Our application of Kahane's guidelines was expanded to the additional topics that our course covers. Accordingly, when teaching logical variables and functions we demonstrated to the students how formal logic is applied to electronic digital-logical systems. Other applications that were demonstrated to the students include logical tools in internet searches and computing problems. These applications followed Swartz et al. (1998), as a variety of secondaryschool science topics are infused with critical and creative thinking.

The OAI (Table 2) emphasizes the a-priori deficiencies in students' reasoning skills (recall reports by Rothenberg, 1997 and Lighthall \& Haycock, 1997). It also stresses the need for reasoning to be taught, as much improvement can be gained by such instruction (Fitzgerald, 2005). This result supports Eshet-Alkalai and Geri's (2007) finding that children lack digital literacy skills. To counter this deficiency, the students were given many assignments in which they had to analyze newspaper articles, political statements, judiciary rulings, and day-to-day life situations. As the emphasis was on application, the students had to describe how their decision-making was based on their critical analysis.

The various components of the course all contributed to the students improving their information literacy. Shapiro and Hughes (1996) claim that computer literacy is the central skill required for information literacy is ever true. Boolean algebra allowed the students to construct filtered information searches. Their critical reasoning skills enabled them to analyze and evaluate information and to determine whether it is relevant for decision-making.

Our second finding relates to the high SAI reported by the students (Table 3). We believe that we were successful in achieving this coupled improvement due to our adherence to Kahane's recommendation regarding applicability and relevance. The students found the material relevant and therefore they responded to it positively, thereby further enhancing their prospects for OAI. Since we applied infusion techniques described by Swartz et al. (1998), students profited in other aspects of life, too. This conclusion is supported by the students' report that they apply their newly gained logic tools in other topics of study. Thus, the positive effects of this course may address a variety of issues raised in recent years by researchers such as Andriole (2006), Johnson, Bartholomew and Miller (2006) and Bartholomew (2003).

As with Pascarella and Terenzini's (1991) findings, we are not so naïve as to believe that a single course is enough to make a persistent change in the students' overall critical thinking. However, our results indicate that there is abundant potential for improvement in students' thinking skills. Thus, we believe that this course should be an introductory course and that training in thinking skills must be provided throughout the entire student curriculum in a similar manner to the recent suggestions made by Thomas et al. (2007).

\section{Generalizability}

There are a number of issues to consider before generalizing these results to other schools and frameworks. First, this course was given to three small groups of students and the results may have been affected by cultural aspects of the population, such as attitudes towards education and political awareness. Second, the research limitations in the research methodology must be also considered when generalizing the results, specifically, the similar structure of the pre-course and 
post-course exam, the limited number of questions in the questionnaire and the relatively small age difference between the groups.

\section{Conclusion}

This paper describes a course designed to improve students' applied logic ability, creative thinking, and critical reasoning and reports how students responded to the course and how this response is assessed both objectively and subjectively. This paper makes several contributions to the fields of education of information technology, applied logic, and critical thinking. First, we described a novel approach to the teaching of critical reasoning. Instead of delaying instruction of critical reasoning to the college years, our course allowed students to acquire those skills at the high school level. We adapted the college level course to a high school level by emphasizing practice over theory, emphasizing applications, providing numerous real-life examples, and by encouraging the students to introduce their experiences into the learning process. This encouragement of student involvement is related to the second contribution of this paper. To motivate the students to be actively engaged with the course material we designed the course so that the subject content is closely related to their academic orientation. We found that this makes the course more effective and interesting to the students. Thirdly, this paper reports our experience teaching this course to three groups with two different academic orientations and two age groups. The results of our experience were that the assessment of students' critical reasoning skills improved both objectively and subjectively. We found that the age affects the OAI with younger students experiencing the higher improvement, whereas academic orientation affects the SAI with the exact sciences students reporting the higher improvement. Despite the limited generalizability of our results, we believe that the ability of our students to improve their critical thinking stresses the need for students in general to acquire critical reasoning skills at the high school level.

In our opinion, this research is an important step in the long path of preparing our students to the rapid changes of the information and digital revolution. We plan to further develop the course curriculum and the second part of the applied logic program in future years. As we gain experience from one year to the next we hope to provide students with better logical reasoning skills, improving their preparation for college and post-college years.

\section{References}

American Library Association (ALA). (1998). Presidential Committee on Information Literacy: Final Report. ALA, Chicago, IL. Retrieved February 15, 2009, from http://www.ala.org/ala/mgrps/divs/acrl/publications/whitepapers/presidential.cfm

Andriole, S. (2006). Business technology education in the 21 st century: The ongoing quest for relevance. Journal of Information Technology Education, 5, 1-12. Retrieved from http://jite.org/documents/Vol5/v5p001-012Andriole36.pdf

Bartholomew, K. (2003). Computer literacy: Is the emperor still exposed after all these years? Journal of Computing Science in Colleges, 20(1), 323-331.

Berg, J. (1998). Applied logic. Rehovot, Israel: Branco Weiss Institute. (In Hebrew).

Boolos, G. S., \& Jeffrey, R. C. (1974). Computability and logic. Cambridge, UK: Cambridge University Press.

Brookfield, S. D. (1987). Developing critical thinkers. San Francisco, CA: Josey-Bass.

Browne, M. N. (2001). Asking the right questions: A guide to critical thinking. Upper Saddle River, NJ: Prentice Hall.

Browne, M. N., \& Keeley, S. (2006). Asking the right questions: A guide to critical thinking (8th ed.). Upper Saddle River, NJ: Prentice Hall, 
Copi, I. M. (1979). Symbolic logic (5th ed.). New York, NY: Macmillan.

Copi, I. M., \& Cohen C. (2004). Introduction to logic (12th ed.). Upper Saddle River, NJ: Prentice Hall.

Epstein, R. L. (2001a). The semantic foundation of logic: Predicate logic. Belmont, CA: Wadsworth.

Epstein, R.L. (2001b). The semantic foundation of logic: Propositional logic (8th ed.). Belmont, CA: Wadsworth.

Epstein, R. L. (2002). 5 ways of saying therefore. Belmont, CA: Wadsworth.

Eshet, Y. (2002). Digital literacy: A new terminology framework and its application to the design of meaningful technology-based environments. In P. Barker \& S. Rebelsky (Eds.), Proceedings of EDMEDIA, 2002 World Conference on Educational Multimedia, Hypermedia and Telecommunications (pp. 493498). Norfolk, VA: Association for the Advancement of Computing in Education.

Eshet-Alkalai, Y. (2004). Digital literacy: A conceptual framework for survival skills in the digital era. Journal of Educational Multimedia and Hypermedia, 13(1), 93-106.

Eshet-Alkalai, Y., \& Geri, N. (2007). Does the medium affect the message? The influence of text representation format on critical thinking. Human Systems Management, 26(4), 269-279.

Fitzgerald, M. A. (2005). Skills for evaluating web-based information. Internet Credibility Symposium, University of Washington, Seattle, April. Retrieved March 25, 2009, from http://www.scribd.com/doc/515336/Fitzgerald-Skills

Gabbay, D., \& Woods, J. (2004). Handbook of the history of logic. Amsterdam: Elsevier.

Godel, K. (1962). On formally undecidable propositions of principia mathematica and related systems. Mineola, NY: Dover.

Hacking, I. (2001). An introduction to probability and inductive logic. Cambridge, UK: Cambridge University Press.

Johnson, D., Bartholomew, K., \& Miller, D. (2006). Improving computer literacy of business management majors: A case study. Journal of Information Technology Education, 5, 77-94. Retrieved from http://jite.org/documents/Vol5/v5p077-094Johnson100.pdf

Kahane, H. (1980). The nature and classification of fallacies. In J. A. Blair \& R. H. Johnson (Eds.), Informal logic: The first international symposium (pp. 31-39). Inverness, CA: Edgepress.

Kahane, H. (1989). The proper subject matter for critical thinking courses. Argumentation, 3(2), 141-147.

Kahane, H., \& Cavender, N. M. (2006). Logic and contemporary rhetoric: The use of reason in everyday life (10th ed.). Belmont, CA: Thomson/Wadsworth.

Katz, R. H., \& Borriello G. (2004). Contemporary logic design (2nd ed.). Upper Saddle River, NJ: Prentice Hall.

Kerka, S. (1999). Consumer education for the information age. Practice Application Brief, 4, 12-15.

Lewis, H. R., \& Papadimitriou, C. H. (1981). Elements of the theory of computation. Upper Saddle River, NJ: Prentice Hall.

Lighthall, L., \& Haycock, K. (1997). Information rich but knowledge poor? Emerging issues for schools and libraries worldwide. Seattle, WA: International Association of School Librarianship.

Markovitz, A. B. (2005). Introduction to logic design (2nd ed.). New York, NY: McGrawHill.

Mano, M. M. (2001). Digital design (3rd ed.). Upper Saddle River, NJ: Prentice Hall.

Pascarella, E. T., \& Terenzini, P. T. (1991). How college affects students: Findings and insights from twenty years of research. San Francisco, CA: Jossey-Bass.

Paul, R. W. (1982). Teaching critical thinking in the 'strong' sense: A focus on self-deception, world views, and a dialectical mode of analysis. Informal Logic, 4(2), 2-7. 
Paul, R. W. (1990). Critical thinking: What every person needs to survive in a rapidly changing world (2nd ed.). Rohnert Park, CA: Center for Critical Thinking and Moral Critique.

Rescher, N. (2001). Paradoxes: Their roots, range and resolution. Chicago, IL: Open Court.

Resnick, M. (2002). Rethinking learning in the digital age. In G. Kirkman (Ed.), The global information technology report 2001-2002: Readiness for the networked world (pp. 32-37). Oxford, UK: Oxford University Press.

Roth, C. H. (2004). Fundamentals of logic design (5th ed.). Belmont, CA: Thompson/Brooks/Cole.

Rothenberg, D. (1997, August 15). How the web destroys the quality of students' research papers. Chronicle of Higher Education, p. A44.

Ruggiero, V. R. (1991). The art of thinking: A guide to critical and creative thought. New York: HarperCollins Publishers.

Sainsbury, R. M. (1995). Paradoxes (2nd ed.). Cambridge, UK: Cambridge University Press.

Salomon, G. (2000). Technology and education in the information age. Tel Aviv: Haifa University/Zemora-Bitan Publishers. (In Hebrew).

Shapiro, J. J., \& Hughes, S. K. (1996). Information literacy as a liberal art. Educom Review, 31(2), 31-35.

Stanford Persuasive Technology Lab. (2004). Stanford Web Credibility Research: (Mostly) Evidence-based articles on web credibility. Retrieved March 13, 2007, from http://credibility.stanford.edu/credlit.html

Swartz, R. J., Fischer, S. D., \& Parks, S. (1998). Infusing the teaching of critical and creative thinking into secondary science: A lesson design handbook. Pacific Grove, CA: Critical Thinking Books and Software.

Thomas, T., Davis, T., \& Kazlauskas, A. (2007). Embedding critical thinking in IS curricula. Journal of Information Technology Education, 6, 327-346. Retrieved from http://jite.org/documents/Vol6/JTEv6p327-346Thomas253.pdf

Turing, A. (1936). On computable numbers, with an application to the Entscheidungsproblem. Proceedings of the London Mathematical Society, 42, 230-265.

Wakerly, J. F. (2005). Digital design: Principles and practices (4th ed.). Upper Saddle River, NJ: Prentice Hall.

\section{Appendix - Examples of the Exam Questions}

As described in the methodology section, the exam comprised three parts. In what follows we provide an example question and answer for each part.

\section{Question \& Answer 1:}

Question: Identify all the arguments in the following sentence/paragraph. Please make sure you identify each argument as a premise or a conclusion and note the relationships between any conclusion and its premises.

"I need to wake up early because my ride to work leaves early and I need to prepare sandwiches because we have no cafeteria at work."

\section{Answer:}

"my ride to work leaves early"

"we have no cafeteria at work"

"I need to prepare sandwiches"

"I need to wake up early tomorrow"
Argument 1 - Premise.

Argument 2 - Premise.

Argument 3, Conclusion of Argument 2.

Argument 4 Conclusion of Argument 1 and Argument 3. 


\section{Question \& Answer 2:}

Question: (Multiple Choice Question) What correctly follows from the following sentence/paragraph?

"All the teachers in Metropolis and half the teachers in Metroville made reservations for the Big Teacher's Conference. Due to severe weather conditions, however, 70\% of Metroville's teachers and $40 \%$ of Metropolis's teachers cancelled their reservation. After being informed of the cancellations, the conference organizers, who assumed that every teacher will arrive with his private car, designated more parking spots to the teachers from Metropolis than those from Metroville. Which of the following statements weakens the organizers' judgment with respect to the parking assignment?

a. $40 \%$ of the teachers in the state live in Metropolis.

b. The number of teachers in Metroville is more than double the number of teachers in Metropolis.

c. Not all the teachers arrived in their private car.

d. $20 \%$ of the teachers of Metrotown made reservations for the conference at the last minute.

Answer: $b$.

\section{Question \& Answer 3:}

Question: Read the following passage:

"Less than one percent of the people receiving parking tickets appeal those tickets. Therefore, one cannot claim that the Parking officers are issuing unwarranted citations.

On which of the following premises is the conclusion above based?
a. People who do not appeal their ticket believe the citation is warranted.
b. The majority of the parking tickets are warranted.
c. Appealing a citation requires time and money.
d. People believe that their chances of winning an appeal are slim.

Answer: a.

\section{Biographies}

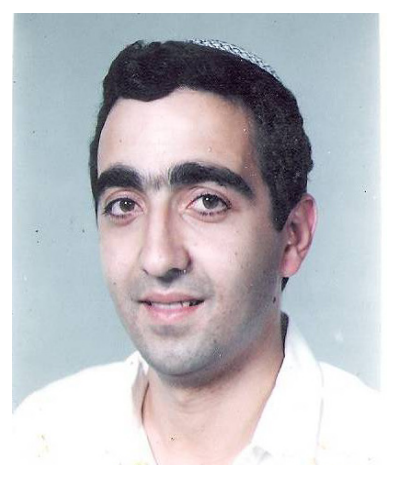

Dr. Dan Bouhnik is currently a lecturer in the Information Science department in Bar Ilan University (BIU) and in the Computer Science department in Jerusalem College of Technology (JCT) in Israel. He taught Computer Science and Logic in High Schools both in Israel and the United States. Dan is the author of a number of books used for teaching Advanced Computer Sciences in High Schools and his professional interests include virtual learning and its effect on the thinking process. 


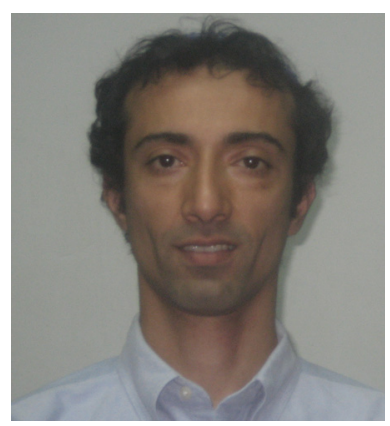

Dr. Yahel Giat is a faculty member in the Department of Industrial Engineering and Management in the Jerusalem College of Technology. $\mathrm{He}$ holds a Ph.D. in Industrial Engineering from the Georgia Institute of Technology and a B.Sc. in Electrical Engineering and Computer Sciences from the Israel Institute of Technology. He has taught high school students computer sciences for more than ten years and his professional interests include the introduction of information systems as tools of economic decision making. 